\title{
Rhodopsin Formation in Drosophila Is Dependent on the PINTA Retinoid-Binding Protein
}

\author{
Tao Wang and Craig Montell \\ Department of Biological Chemistry, The Johns Hopkins University School of Medicine, Baltimore, Maryland 21205
}

\begin{abstract}
Retinoids participate in many essential processes including the initial event in photoreception. 11-cis-retinal binds to opsin and undergoes a light-driven isomerization to all-trans-retinal. In mammals, the all-trans-retinal is converted to vitamin A (all-trans-retinol) and is transported to the retinal pigment epithelium (RPE), where along with dietary vitamin A, it is converted into 11-cis-retinal. Although this cycle has been studied extensively in mammals, many questions remain, including the specific roles of retinoid-binding proteins. Here, we establish the Drosophila visual system as a genetic model for characterizing retinoid-binding proteins. In a genetic screen for mutations that affect the biosynthesis of rhodopsin, we identified a novel CRAL-TRIO domain protein, prolonged depolarization afterpotential is not apparent (PINTA), which binds to all-trans-retinol. We demonstrate that PINTA functions subsequent to the production of vitamin A and is expressed and required in the retinal pigment cells. These results represent the first genetic evidence for a role for the retinal pigment cells in the visual response. Moreover, our data implicate Drosophila retinal pigment cells as functioning in the conversion of dietary all-trans-retinol to 11-cis-retinal and suggest that these cells are the closest invertebrate equivalent to the RPE.
\end{abstract}

Key words: rhodopsin; phototransduction; retinoid-binding protein; pigment cells; CRAL-TRIO domain; retinal

\section{Introduction}

Vitamin A (all-trans-retinol) and other retinoids are critical for processes ranging from development to visual pigment regeneration, neuronal plasticity, and cell proliferation (for review, see Simoni and Tolomeo, 2001; Thompson and Gal, 2003; Mey and McCaffery, 2004). Defects in retinoid levels are associated with many forms of cancer as well as neurodegenerative diseases including retinitis pigmentosa, Parkinson's disease, and Huntington's disease (for review, see Simoni and Tolomeo, 2001; Thompson and Gal, 2003; Mey and McCaffery, 2004). In contrast to mammals, the fruit fly, Drosophila melanogaster, appears to require retinoids exclusively in the retina (Harris et al., 1977).

The retinoids required for Drosophila and mammalian phototransduction (3-hydroxy-11-cis-retinal and 11-cis-retinal, respectively) (Wald, 1968; Vogt and Kirschfeld, 1984; Tanimura et al., 1986) bind to the opsin to form rhodopsin (Rh). Light results in a cis-to-trans isomerization of the chromophore, and this transformation represents the only light-driven step during phototransduction. Regeneration of the cis-retinal in mammalian rods involves release of the all-trans-retinal from the opsin and formation of vitamin A, which is transported to the retinal pigment epithelium (RPE) and converted into 11-cis-retinal. A more rapid retinoid cycle leading to regeneration of the cone rhodopsins occurs in the Müller cells (Mata et al., 2002). The 11-cisretinal is then returned to the rods and cones. The critical role for

\footnotetext{
Received March 14, 2005; revised April 14, 2005; accepted April 20, 2005.

This work was supported by a grant to C.M. from the National Eye Institute (EY08117). We thank Mike Sepanski for preparing sections of compound eyes, Drs. J. Saari and J. Crabb for the CRALBP antibodies, R. Crouch for 11-cisretinal, G. Halder for the hippo mutant flies, and Hui Cheng for advice and technical help.

Correspondence should be addressed to Craig Montell at the above address. E-mail: cmontell@jhmi.edu. D0I:10.1523/JNEUROSCI.0995-05.2005

Copyright $\odot 2005$ Society for Neuroscience $\quad$ 0270-6474/05/255187-08\$15.00/0
}

this cycle is reflected by the severe retinal diseases resulting from mutations disrupting two retinal dehydrogenases and two retinoid-binding proteins (RBPs) (for review, see Thompson and Gal, 2003).

Retinoids must associate with RBPs, because they are hydrophobic. In addition, some RBPs are thought to promote transfer of retinoids between cell types, whereas others are proposed to sequester retinoids to create concentration gradients that facilitate reactions that would otherwise be unfavorable (Noy, 2000; Gonzalez-Fernandez, 2002). However, the specific roles of many RBPs are unresolved.

In Drosophila, light does not cause the chromophore to release from the opsin. The all-trans-retinal is converted to cis-retinal in photoreceptor cells in a light- rather than an enzyme-dependent manner. Nevertheless, the RBPs and enzymes necessary for conversion of free all-trans- to cis-retinal must exist, because dietary vitamin $\mathrm{A}$ is sufficient for production of the 11-cis-retinal. One enzyme that functions in the transformation of the retinal to the chromophore is an oxidoreductase encoded by the neither inactivation nor afterpotential G (ninaG) locus (Sarfare et al., 2005). In addition, two genes (ninaB and ninaD) function outside the retina for production of vitamin A (Stephenson et al., 1983; Gu et al., 2004) and encode a $\beta, \beta$-carotene-15,15'-dioxgenase and a class B scavenger receptor, respectively (von Lintig et al., 2001; Kiefer et al., 2002). However, the RBPs required for Drosophila vision have not been identified.

Here, we describe the isolation of the prolonged depolarization afterpotential (PDA) is not apparent (pinta) locus, which encodes an RBP. The PINTA protein bound preferentially to all-trans-retinol and was required subsequent to the formation of vitamin A. Elimination of PINTA profoundly effected production of rhodopsin and the visual response. Furthermore, unlike 
other Drosophila proteins required for the visual response, PINTA was required in retinal pigment cells (PCs). These data indicate that the retinal pigment cells represent the closest Drosophila counterpart to the RPE, which in mammals is also required for conversion of dietary vitamin A to 11-cis-retinal.

\section{Materials and Methods}

Fly stocks. The pinta mutant was isolated by performing ethylmethane sulfonate mutagenesis and screening for third-chromosome mutations affecting the PDA, as we have described recently (Wang et al., 2005). The PDA is so named because there is an afterpotential after cessation of a blue light stimulus. The Bloomington Stock Center (Bloomington, IN) was the source for the third-chromosome deficiency kit and the following stocks: BG00076, $\mathrm{P}[\mathrm{PZ}] 1$ (3)rQ178r, EY05255, $\mathrm{P}[$ Gaw-B]LL54, ninaE $E^{I 17}$ (deletion disrupting ninaE, which encodes Rh1), and $\mathrm{P}[G M R$ GAL4]. EP738, EP3575, EP561, EP3224, and EP3303 were obtained from the Szeged Stock Center (Szeged, Hungary). Dr. W. Pak (Purdue University, West Lafayette, IN) provided nina $E^{P 332}$ and ninaD ${ }^{P 246}$, and Dr. C. Desplan (New York University, New York, NY) supplied the $\mathrm{P}[$ ninaE-GAL4].

Electroretinogram recordings. Electroretinogram (ERG) recordings were performed as described previously (Wes et al., 1999). Briefly, two glass microelectrodes filled with Ringer's solution were inserted into small drops of electrode cream placed on the surfaces of the compound eye and the thorax. A Newport (Irvine, CA) light projector (model 765) was used for stimulation. The ERGs were amplified with a Warner Instruments (Hamden, CT) IE-210 electrometer and recorded with a MacLab/4s analog-to-digital converter and the Chart version 3.4/s program (AD Instruments, Colorado Springs, CO). All recordings were performed at room temperature.

Mapping of mutation responsible for the inactivation phenotype. The pinta mutation was uncovered by $D f(3 R) 93 F[x 2]$ and $D f(3 R) h h$. $D f(3 R) e-G C 3$ and $D f(3 R) 23 D 1$ did not uncover the mutation (see Fig. 2A). Therefore, the mutation responsible for the pinta phenotype localized to 93F-94B. The breakpoints of $D f(3 R) h h$ and $D f(3 R) 23 D 1$ were further mapped using P-element inserts. rQ178 was uncovered by $D f(3 R) h h$, but EP561 was not. EY05255 but not EP3303 was uncovered by $D f(3 R) 23 D 1$ (see Fig. 2A). Based on these data, the pinta locus was localized to the interval spanning 94A6-94A14.

Generation of transgenic flies. CG13848 (pinta) genomic DNA was excised from BAC30J14 and introduced into the PstI site of pCaSpeR-4 (Thummel and Pirrotta, 1992). To express the CG13848 ( pinta) cDNA under the control of the upstream-activating sequence (UAS) promoter, the cDNA [expressed sequence tag (EST) clone RH67675; Invitrogen, San Diego, CA] was subcloned between the EcoRI and XhoI sites of the pUAST vector (Brand and Perrimon, 1993). To express cellular retinaldehyde-binding protein (CRALBP) and cellular retinol-binding protein type I (CRBPI) in flies, the human cDNAs (EST clones 4861258 and 5782072, respectively; Invitrogen) were subcloned between the NotI and $\mathrm{XbaI}$ sites of the transformation vector pCaspeR-hs (Thummel and Pirrotta, 1992), under the control of the heat shock protein 70 promoter. The CRBP1 cDNA was fused to a C-terminal MYC-tag. The constructs were injected into $w^{1118}$ embryos, and transformants were identified on the basis of eye pigmentation.
Fusion proteins. The full-length pinta cDNA was subcloned into both pGEX5X-1 (Amersham Biosciences, Arlington Heights, IL) and pRSETA vector (Invitrogen) to create glutathione $S$-transferase (GST)- and polyhistidine-tagged proteins, respectively. The human cellular retinoic acid (RA)-binding protein I (CRABP-I) cDNA (EST 4864636) was also subcloned into pGEX5X-1 vector. The GST fusion proteins were expressed in Escherichia coli BL21 codon-plus (Stratagene, La Jolla, CA) and purified using glutathione agarose beads (Amersham Biosciences, Piscataway, NJ). The polyhistidine (His tag) fusion protein was also expressed in E. coli BL21 codon-plus and purified using nickel-nitrilotriacetic acid agarose beads (Qiagen, Hilden, Germany).

Antibodies. Anti-PINTA antibodies were generated in rabbits (Covance, Princeton, NJ) inoculated with the recombinant GST-PINTA fusion proteins. Monoclonal anti-Rh1 and anti-tubulin antibodies were purchased from the Developmental Studies Hybridoma Bank (Iowa City, IA). Drs. J. Saari (University of Washington, Seattle, WA) and J. Crabb (Cleveland Clinic Foundation, Cleveland, $\mathrm{OH}$ ) supplied the antiCRALBP antibodies, and the anti-Rh4 polyclonal antibodies were a gift from Dr. C. Zuker (University of California San Diego, La Jolla, CA). The anti-No Receptor Potential A (anti-NORPA; a phospholipase C $\beta$ ) antibodies were prepared as described previously (Wang et al., 2005).

Western blots. To detect Rh1, Rh4, or PINTA on Western blots, samples were homogenized in SDS sample buffer with a pellet pestle (Kimble-Kontes, Vineland, NJ), and the proteins were fractionated by SDS-PAGE. The proteins were transferred overnight at $25 \mathrm{~V}$ to Immobilon-P transfer membranes (Millipore, Bedford, MA) in Trisglycine buffer. The blots were probed with rabbit anti-PINTA primary antibodies (1:2000 dilution), mouse anti-Rh1 antibodies, or rabbit anti-
A

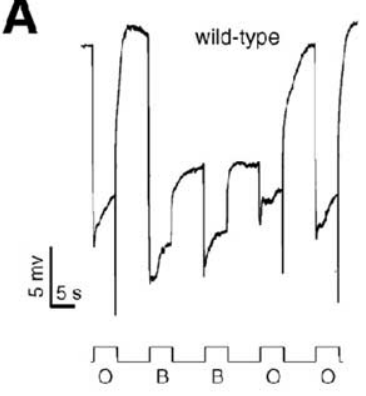

D

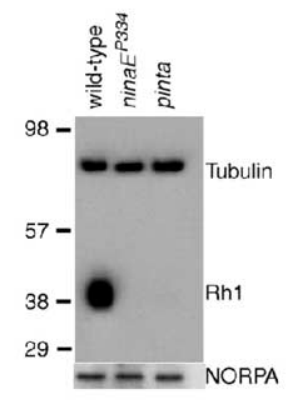

B
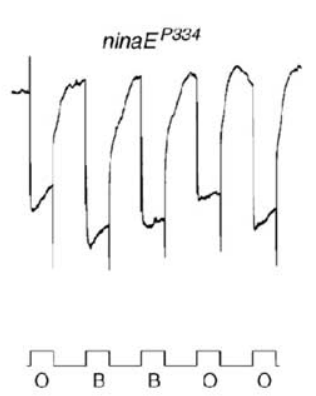

E

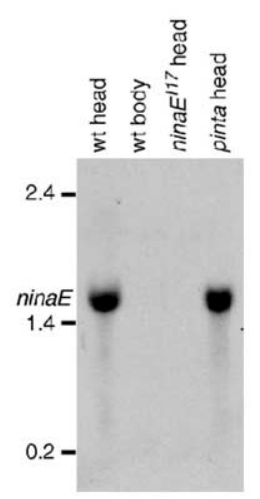

C

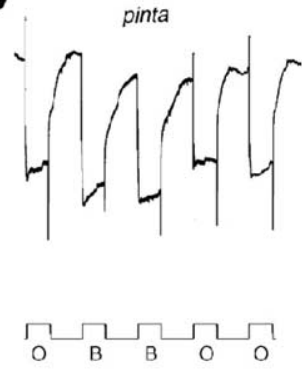

$\mathbf{F}$

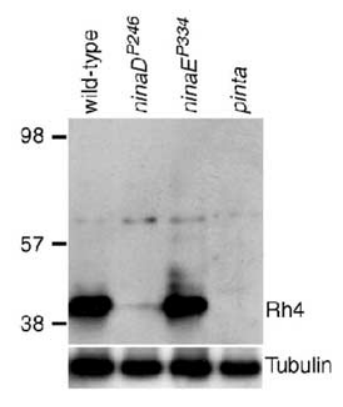

Figure 1. Rhodopsin biosynthesis and PDA defects in pinta. A-C, ERG paradigm that elicits a PDA in wild type, but not mutants, with reduced Rh1 levels. Flies ( $<2 \mathrm{~d}$ after eclosion) were dark-adapted for 1 min and subsequently exposed to $5 \mathrm{~s}$ pulses of orange light $(0)$ or blue light $(B)$ interspersed by $7 \mathrm{~s}$, as indicated. A PDA is induced in wild type by blue light and terminated by orange light. $\boldsymbol{A}$, Wild type $\left(w^{1118}\right) ; \boldsymbol{B}$, ninaE ${ }^{P 334} ; \boldsymbol{C}$, pinta. $\boldsymbol{D}, \mathrm{Rh} 1$ is reduced in ninaE $E^{P 334}$ and pinta flies. Western blots containing extracts prepared from fly heads ( $2 \mathrm{~d}$ after eclosion) were probed with anti-Rh1 and anti-tubulin antibodies. Molecular weight markers (in kilodaltons) are indicated to the left. A parallel blot containing the same extracts was probed with anti-NORPA antibodies. $\boldsymbol{E}$, ninaE mRNA levels assayed by Northern blot analysis. Each lane contained $20 \mu \mathrm{g}$ of total RNA. Similar signals in each lane were obtained after reprobing with a ribosomal protein 49 probe (data not shown). Single-stranded RNA markers are indicated to the left. wt, Wild type. $\boldsymbol{F}$, Western blot showing Rh4 expression was reduced in pinta heads. The Western blot was probed with anti-Rh4 antibodies. The same blot was reprobed with anti-tubulin antibodies. 
Rh4 antibodies and subsequently with anti-rabbit or mouse IgG peroxidase conjugate (Sigma, St. Louis, MO) or ${ }^{125}$ I-labeled protein A (ICN Biochemicals, Costa Mesa, CA). The signals were detected using ECL reagents (Amersham Biosciences) or a phosphoimager.

Northern blots. Total RNAs were prepared using Trizol reagent (Invitrogen) and fractionated on 3\% formaldehyde, $1.5 \%$ agarose gels. The RNAs (20 $\mu \mathrm{g}$ of each sample) were transferred to nitrocellulose membranes and allowed to hybridize with ${ }^{32} \mathrm{P}$-labeled probes, which were prepared using random primers and a ninaE reverse transcription-PCR product (nucleotides $600-950$ of the ninaE mRNA) as the template. The hybridization was performed at $65^{\circ} \mathrm{C}$ in $7 \%$ SDS, 2 mM EDTA, $250 \mu \mathrm{g} / \mathrm{ml}$ salmon sperm DNA, $0.5 \mathrm{M} \mathrm{Na}_{2} \mathrm{HPO}_{4}, \mathrm{pH}$ 7.2, and the membranes were washed at $65^{\circ} \mathrm{C}$ in $0.1 \times$ SSC.

Retinoid-binding assays. Isotope retinoic acid-binding assays were performed according to procedures similar to those described previously (Bernstein et al., 1995). Briefly, $1 \mu \mathrm{g}$ of recombinant proteins GSTCG13848, GST-CRABP, and GST were incubated in a $100 \mu \mathrm{l}$ of solution containing $25 \mathrm{~mm}$ Tris- $\mathrm{HCl}$, pH 7.4, 1 mм EDTA, 1 mm DTT, and 0.01 $\mu \mathrm{Ci}\left[{ }^{3} \mathrm{H}\right] \mathrm{RA}$ (NEN, Boston, MA) in the presence or absence of $20 \mu \mathrm{M}$ RA. After an incubation for $1 \mathrm{~h}$ at room temperature, the unbound $\left[{ }^{3} \mathrm{H}\right] \mathrm{RA}$ in the samples was removed by adsorption to dextran-coated charcoal (50 $\mu \mathrm{l}$ of $0.25 \%$ activated charcoal, $0.025 \%$ dextran, $25 \mathrm{~mm}$ Tris- $\mathrm{HCl}, \mathrm{pH}$ 7.4) and centrifugation at $10,000 \times g$. The bound $\left[{ }^{3} \mathrm{H}\right] \mathrm{RA}$ was counted in $5 \mathrm{ml}$ of Biodegradable Counting Scintillant scintillation fluid (Amersham Biosciences).

Fluorescence retinoid-binding measurements were performed at $25^{\circ} \mathrm{C}$ in $1 \times$ PBS, pH 7.4, using $0.1 \mu \mathrm{M}$ His tag recombinant proteins using procedures similar to those described previously (Cogan et al., 1976; Li et al., 1987). The protein solution was excited at $287 \mathrm{~nm}$, and the emission peak was monitored at $339 \mathrm{~nm}$. The fluorescence was measured at a

variety of retinoid concentrations. The dissociation constant of a single binding site $\left(K_{\mathrm{d}}\right)$ and the number of binding sites $(n)$ were evaluated by linear least-squares plots of the following equation: $K_{\mathrm{d}}=C_{0}(1-\alpha) / \alpha-$ $P_{0} / n(1-\alpha)$. This equation was derived from the mass law equation, where $\alpha$ is the fraction of free binding sites, $C_{0}$ is the total retinoid concentration, $P_{0}$ is the total protein concentration, and $n$ is the number of binding sites. In the following equation: $\alpha=\left(F_{\mathrm{o}}-F\right) /\left(F_{\mathrm{o}}-F_{\max }\right), F$ represents the fluorescence intensity at a given $C_{0}, F_{\max }$ represents the fluorescence intensity after saturation of all the apoprotein molecules, and $F_{\mathrm{o}}$ is the initial fluorescence intensity in the absence of retinoid. 11-cis-retinal was obtained from Dr. R. Crouch (University of South Carolina, Charleston, SC), and other retinoids were purchased from Sigma.

In situ hybridizations. Digoxigenin (DIG)-labeled sense or antisense RNA probes were prepared using the full-length pinta cDNA (pcDNA3pinta) in conjunction with either SP6 or T7 polymerase. The RNAs were allowed to hybridize to frozen $8 \mu \mathrm{m}$ sections of adult fly heads at $70^{\circ} \mathrm{C}$ in $50 \%$ formamide, $5 \times$ SSC, $0.02 \%$ SDS, and $1 \times$ blocking buffer (Roche Products, Welwyn Garden City, UK). The sections were subsequently incubated with anti-DIG alkaline phosphatase-conjugated antibodies and the signals detected using nitroblue-tetrazolium-chloride and 5-bromo-4-chlor-indolyl-phosphate (Roche Products).

\section{Results}

\section{A mutant defective in production of rhodopsin}

To identify new genes that function in Drosophila phototransduction, we screened the third chromosome for mutations that cause defects in the visual response by performing ERG recordings (for details, see Wang et al., 2005). ERGs are extracellular recordings that measure the summed responses of all retinal cells to light. To conduct the screen, we used a paradigm that previously lead to the identification of mutations that disrupt production of the major

A

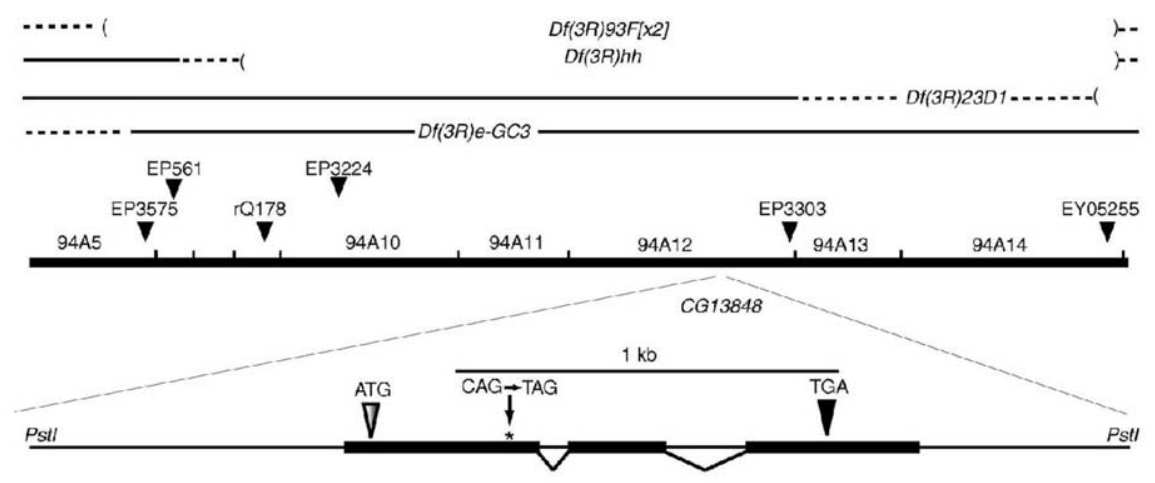

B

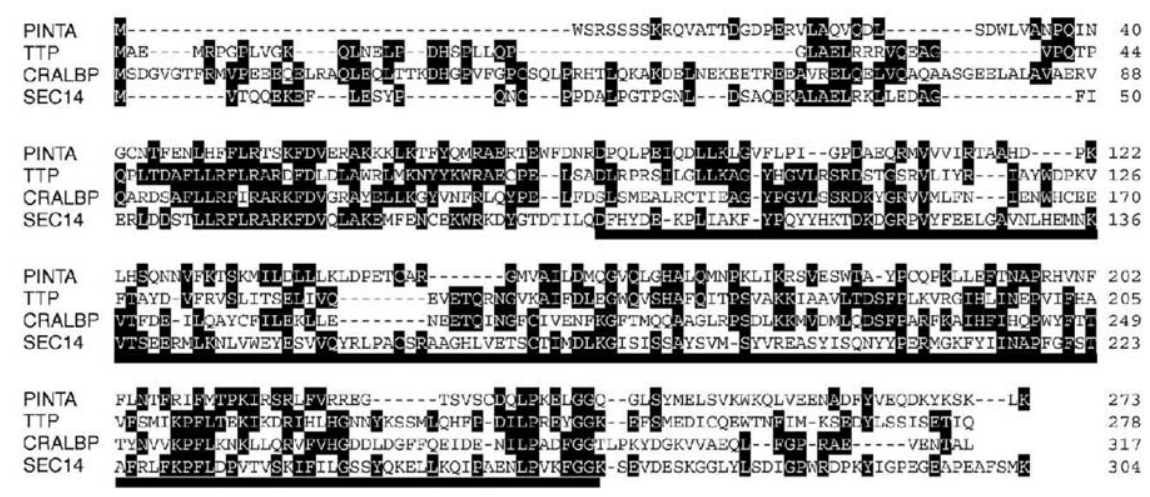

Figure 2. The pinta locus. $A$, Mapping of the pinta mutation. The pinta gene was localized to $94 \mathrm{A6}-94 \mathrm{~A} 14$ using a series of deficiencies. The nonsense mutation (CAG $\rightarrow$ TAG; residue 90 in wild type) is indicated. $\boldsymbol{B}$, Alignment of the PINTA amino acid sequence with TTP, CRALBP, and SEC14. Identical residues, which are found in at least two proteins, are enclosed in black boxes. The CRAL-TRIO domain is indicated by the solid line underneath the corresponding sequence. The running tally of amino acids is indicated to the right. rhodopsin, Rh1 (for review, see Pak and Leung, 2003). In response to orange light, wild-type flies display a rapid corneal negative response, which quickly returns to the dark state after cessation of the light stimulation (Fig. 1A). After exposure to blue light, there is a prolonged depolarization afterpotential (Fig. 1A) after cessation of the light stimulus, which results from stable conversion of the Rh1 into the light-activated form (metarhodopsin). The PDA is terminated by subsequent exposure to a pulse of orange light (Fig. $1 \mathrm{~A}$ ) as a result of conversion of the metarhodopsin to inactive rhodopsin.

We identified 10 mutations that either eliminated or greatly reduced the PDA, which fell into three complementation groups. These included mutations in the two previously described third-chromosomal genes that eliminate the PDA: ninaE (eight alleles) (Fig. $1 B$ ) and ninaB (one allele). The ninaE locus encodes the structural gene for the Rh1 opsin (O'Tousa et al., 1985; Zuker et al., 1985), and ninaB encodes a $\beta, \beta$-carotene-15,15'-dioxgenase required external to the retina for biogenesis of the chromophore (von Lintig et al., 2001; Gu et al., 2004). The remaining mutation, referred to as pinta (Fig. 1C), failed to complement either nina mutant and therefore appeared to represent a new locus required for production of the PDA. 
The dramatic reduction in the pinta PDA indicated that there was a defect in Rh1 function. To determine whether the concentration of Rh1 was reduced in pinta, we probed Western blots with anti-Rh1 antibodies and found that the level of Rh1 was dramatically decreased (Fig. 1D). The diminished Rh1 concentration was not attributable to an effect on Rh1 transcription, because the RNA was present in similar amounts in wild-type and pinta heads (Fig. $1 E$ ).

In addition to Rh1, which is the predominant Drosophila rhodopsin, there are four minor rhodopsins (Rh3-6) detected in the compound eye (for review, see Montell, 1999). Rh1 is localized to the major class of the photoreceptor cells, the R1-6 cells (O’Tousa et al., 1985; Zuker et al., 1985; De Couet and Tanimura, 1987), whereas the four minor opsins are expressed in nonoverlapping subsets of the smaller R7 and R8 cells (Montell et al., 1987; Fortini and Rubin, 1990; Chou et al., 1996, 1999; Huber et al., 1997; Papatsenko et al., 1997). We checked the protein levels of one of the minor opsins, Rh4, and found that the concentration of this protein was also diminished in pinta (Fig. $1 F$ ); however, the levels of other retinal proteins, such as the phospholipase C encoded by norpA (Bloomquist et al., 1988), were unaffected (Fig. 1D).

\section{PINTA is a CRAL-TRIO domain protein}

To identify the altered gene responsible for the pinta phenotype, we mapped the site of the mutation to the 94A4-A14 region (Fig. 2A) (see Materials and Methods), which included 27 predicted and known genes (http://flybase.bio.indiana.edu). To find the most likely candidate gene among this set, we considered whether expression of any of the genes was enriched in the compound eyes, because nearly all of the known genes that function in phototransduction were expressed predominantly in the eyes (Xu et al., 2004). Among the 27 genes in the 94A4-A14 interval, only one (CG13848) was expressed at higher levels in wild-type heads (2.6-fold) than in mutant heads devoid of eyes [sine oculis (so); disrupts a homeodomain transcription factor required for eye formation]. The 273 amino acid CG13848 protein appeared to be the PINTA protein, because there was a translation stop codon in place of residue 90 (Fig. $2 A, B$ ).

To confirm that CG13848 was the pinta locus, we introduced a transgene encoding CG13848 into pinta flies. This transgene restored normal levels of the CG13848 and Rh1 proteins in the mutant flies (Fig. $3 A, B$ ) and a wild-type PDA (Fig. 3C,D).

The PINTA protein shares significant amino acid identities with CRAL-TRIO domain proteins that bind to small lipophilic molecules (Panagabko et al., 2003) (Fig. 2 B). These include the $\alpha$-tocopherol-binding protein (TTP; $27 \%$ identical over 218 residues) (Sato et al., 1993), CRALBP (23\% identical over 196 residues) (Crabb et al., 1988), and the yeast phosphatidylinositol transfer protein Sec14 (26\% identical over 210 residues) (Szolderits et al., 1989).

\section{PINTA is a retinoid-binding protein}

The presence of the CRAL-TRIO domain suggests that PINTA binds a small lipophilic molecule. Because one of the PINTA related proteins, CRALBP, is a retinoid-binding protein, and the chromophore for the Drosophila rhodopsins is a retinal derivative, we tested the proposal that PINTA is a retinoid-binding protein. To perform the binding experiments, we used a GSTPINTA fusion protein purified on a glutathione column. We found that GST-PINTA, but not GST alone, bound to ${ }^{3}[\mathrm{H}] \mathrm{RA}$ as effectively as GST fused to CRABP-I (Fig. 4A) (Astrom et al., 1991).

The three main classes of retinoids are retinol, retinal, and
A

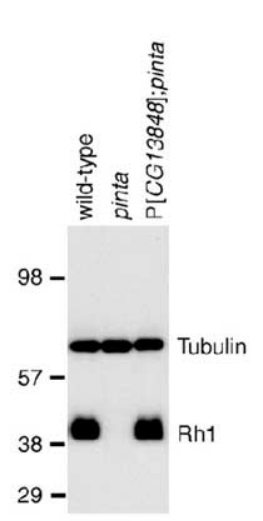

C

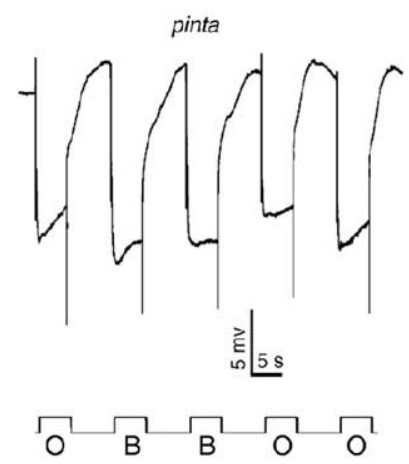

B

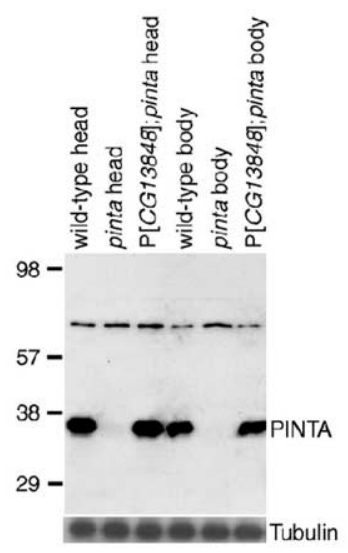

Figure 3. Rescue of the rhodopsin synthesis and PDA defects in pinta by a pinta ${ }^{+}$transgene. $A, \mathrm{Rh} 1$ expression is restored in $\mathrm{P}[\mathrm{CG} 13848]$; pinta flies. Head extracts were prepared from flies $2 \mathrm{~d}$ after eclosion and probed with anti-Rh1 and anti-tubulin antibodies. B, PINTA is absent in pinta flies and restored by the P[CG13848] transgene. The same blot was reprobed with antitubulin antibodies. The identity of the high-molecular-weight crossreacting band, which is present in both wild-type and pinta flies, is not known. C, PDA was eliminated in pinta flies. $\boldsymbol{D}$, PDA was restored in P[CG13848]; pinta flies. The ERG paradigm using orange light (0) and blue light (B) was as described in Figure $1 \mathrm{~A}$.

retinoic acid. To determine which of these retinoids bound to PINTA with the highest affinity, we used purified polyhistidinetagged PINTA and assayed for quenching of the intrinsic fluorescence from internal tryptophans by binding to retinoids. Using retinoids in the all-trans configuration, we found that PINTA had the greatest affinity to retinol (25 nM) (Fig. $4 B-D)$, followed by retinoic acid ( $43 \mathrm{~nm}$ ) (Fig. $4 D$, supplemental Fig. $1 A$, available at www.jneurosci.org as supplemental material). The affinity of retinal ( $89 \mathrm{~nm}$ ) was the lowest (Fig. $4 D$, supplemental Fig. $1 D$, available at www.jneurosci.org as supplemental material). The affinities of the cis forms of those retinoids tested were lower than the all-trans-retinoids. These include 11-cis-retinal (286 nM) and 9-cis-retinoic acid (317 nM) (Fig. 4D, supplemental Fig. 1C,D, available at www.jneurosci.org as supplemental material).

\section{Vitamin A supplementation does not rescue the pinta phenotype}

The phenotypes resulting from mutations of either of two nina genes known to be required for retinal metabolism (ninaB and ninaD) are rescued by supplementation of the food with vitamin A. Therefore, we tested whether the severity of the pinta pheno- 


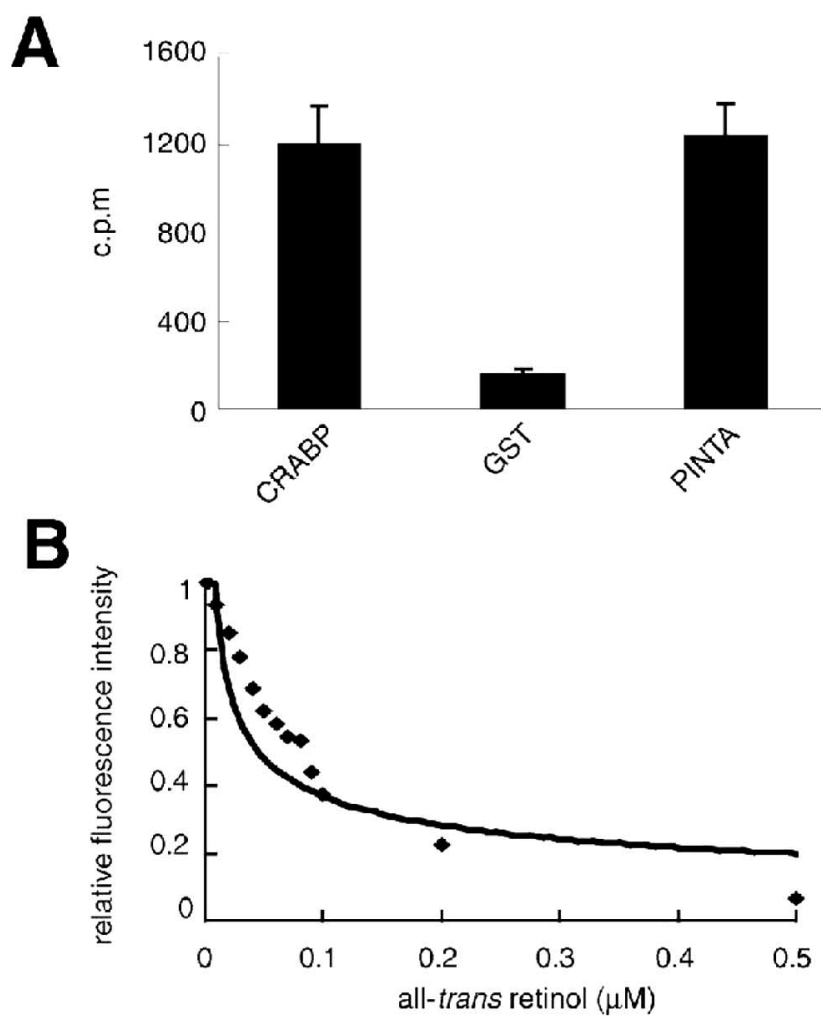

C

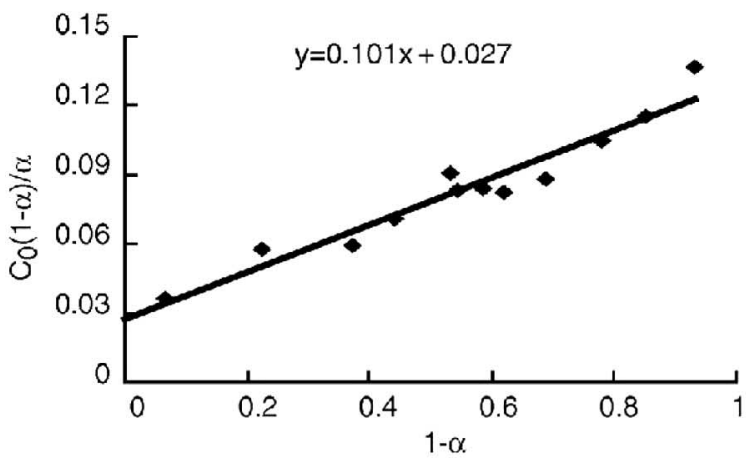

D

\begin{tabular}{|c|c|}
\hline Substrate & $\mathrm{K}_{\mathrm{d}}(\mu \mathrm{M})$ \\
\hline all-trans retinoic acid & $0.043 \pm 0.004$ \\
\hline all-trans retinol & $0.025 \pm 0.002$ \\
\hline all-trans retinal & $0.089 \pm 0.005$ \\
\hline 11-cis retinal & $0.286 \pm 0.036$ \\
\hline 9-cis retinoic acid & $0.317 \pm 0.029$ \\
\hline
\end{tabular}

Figure 4. PINTA is a retinoid-binding protein. $A$, Binding of $\left[{ }^{3} \mathrm{H}\right]$ all-trans-retinoic acid to GST-CRABP, GST, and GST-PINTA. The levels of bound [ $\left.{ }^{3} \mathrm{H}\right]$ all-trans-retinoic acid were measured using a scintillation counter. The SEMs (error bars) were based on three sets of experiments. $\boldsymbol{B}$, Fluorometric titration of $0.1 \mu \mathrm{m}$ solutions of His-PINTA was performed with all-transretinol. Fluorescence emission was measured at $339 \mathrm{~nm}$ after excitation at $287 \mathrm{~nm}$. C, Linear plot of $C_{0}(1-\alpha) / \alpha$ versus $1-\alpha . \alpha$ is the fraction of free binding sites. In the equation $y=$ $0.101 x+0.027, K_{d}=0.027$ and $n=1 . D, K_{d}$ values for PINTA/retinoid interactions. Fluorescence titration (supplemental Fig. 1, available at www.jneurosci.org as supplemental material) was used to measure the $K_{\mathrm{d}}$ values. The SEMs were based on three sets of experiments.
A

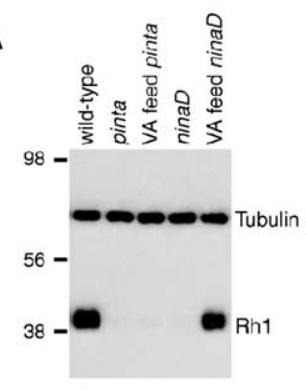

C

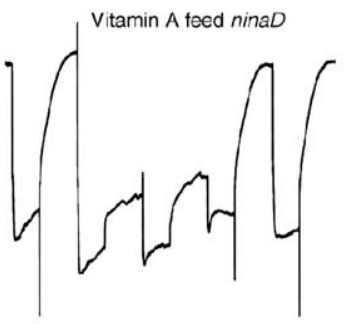

E

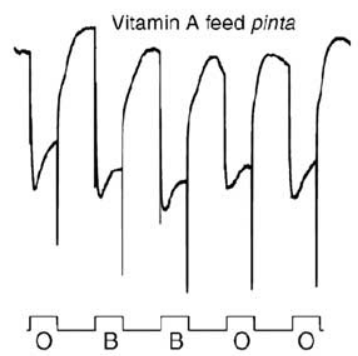

B

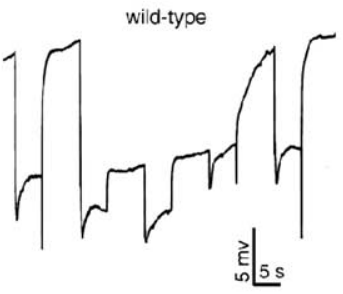

D

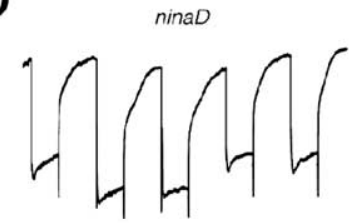

$\mathbf{F}$

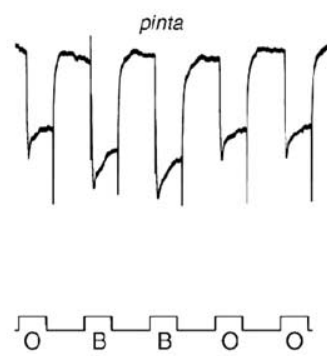

Figure 5. PINTA functions downstream of vitamin A production. $\boldsymbol{A}$, Normal Rh1 levels are restored in ninaD $D^{P 246}$ flies (Stephenson et al., 1983) but not in pinta flies by feeding with vitamin A (VA). Both ninaD ${ }^{P 246}$ and pinta flies were fed either normal food or instant food with $10 \mu \mathrm{g} / \mathrm{ml}$ all-trans-retinal. A Western blot containing fly head extracts ( $2 \mathrm{~d}$ after eclosion) was probed with anti-Rh1 or anti-tubulin antibodies. $\boldsymbol{B}-\boldsymbol{F}$, PDAs performed using the same paradigm as in Figure $1 A$. Flies were fed normal food unless indicated otherwise. $\boldsymbol{B}$, Wild type; $\boldsymbol{C}$, vitamin A-fed ninaD; $\boldsymbol{D}$, ninaD; $\boldsymbol{E}$, vitamin A-fed pinta; $\boldsymbol{F}$, pinta. 0 , Orange light; $B$, blue light.

type was reduced by addition of vitamin A. Consistent with previous studies (Stephenson et al., 1983), the decreases in Rh1 levels and the PDA were reversed in ninaD flies fed on vitamin A-containing media (Fig. $5 A, C, D$ ). However, addition of vitamin A had no impact on the pinta phenotype (Fig. 5A,E,F). These results suggest that pinta functions downstream of ninaB and ninaD in retinal metabolism.

Expression of PINTA is enriched in pigment cells

To address the expression pattern of pinta, we performed in situ hybridizations and Western blots. We found that the PINTA protein was detected initially during the third-instar larval stage and was expressed at maximal levels in adult heads (Fig. 6A, B). Because the anti-PINTA antibodies were ineffective for immunostaining, we performed in situ hybridizations and Western blots. We found that the pinta RNA was enriched in the retina and was also expressed in the lamina, medulla, and optic lobes, consistent with the microarray analyses (Fig. 6 C). In addition, we found that the level of the PINTA protein was reduced in the heads of the eyeless mutant so (Fig. 6B).

The two major cell types in the compound eye are the photoreceptor cells and pigments cells. To determine whether PINTA was enriched in either of these cell types, we performed Western 
blots using extracts prepared from fly heads missing either photoreceptor cells or retinal pigments cells. We found that the concentration of PINTA was similar in wild type and in a mutant, glass (disrupts a zinc finger transcription factor), missing photoreceptor cells (Fig. 6B). To generate flies missing the retinal pigment cells, we used the GAL4/UAS system (Brand and Perrimon, 1993) to direct expression of the proapoptotic gene reaper (rpr), specifically in the pigment cells (PC-GAL4; $U A S-r p r)$. In these flies, the concentration of PINTA was reduced to a similar extend (approximately threefold) as in so heads (Fig. 6B). PINTA was expressed at elevated levels in a mutant (hippo; disrupts a serine/threonine protein kinase 20 family protein kinase), which produced a surplus of pigment cells (Udan et al., 2003; Wu et al., 2003) (Fig. 6B). These results indicate that PINTA is enriched in retinal pigment cells.

\section{Requirement for pinta in pigment cells} Both ninaB and ninaD activity are required outside of the retina for rhodopsin biogenesis ( $\mathrm{Gu}$ et al., 2004). Conversely, nina $G$ functions in the retina, although the cellular requirement is not known (Sarfare et al., 2005). To address whether pinta functions in pigment or photoreceptor cells, we generated UAS-pinta transgenic flies and crossed the transgenic animals with GAL4 lines, which direct different patterns of expression. We found that expression of pinta throughout the retina, using $\mathrm{P}[G M R-G a l 4]$, fully rescued the pinta phenotype (Fig. 7A-D). Expression of PINTA exclusively in photoreceptor cells, using $\mathrm{P}[$ ninaE-GAL4] in combination with $\mathrm{P}[U A S$-pinta], did not reduce the severity of the pinta phenotype (Fig. $7 A, E$ ). However, the pinta phenotype was rescued by expressing PINTA exclusively in pigment cells using a pigment cell GAL4 line (Fig. $7 A, F$ ). These results demonstrate that pinta is required in retinal pigment cells for biosynthesis of rhodopsin.

\section{Discussion}

In the current work, we demonstrate that PINTA is a new member of the CRAL-TRIO family of proteins, which bind small lipophilic molecules such as retinal, inositol, and vitamin E (Panagabko et al., 2003). Disruption of the pinta locus causes severe defects in rhodopsin production, resulting in an electrophysiological phenotype similar to that induced by other mutations affecting rhodopsin biosynthesis.

Because rhodopsin is comprised of an opsin moiety linked to a chromophore, a reduction in rhodopsin levels could result from mutations affecting either the protein or retinal subunits (Stephenson et al., 1983). Genetic approaches in Drosophila have led to the identification of genes essential for the synthesis and transport of the opsin (O’Tousa et al., 1985; Zuker et al., 1985; Colley et al., 1991), several enzymes required for biosynthesis of vitamin A (Stephenson et al., 1983; von Lintig et al., 2001; Kiefer et al., 2002) or subsequent to the production of this precursor for gen-
B
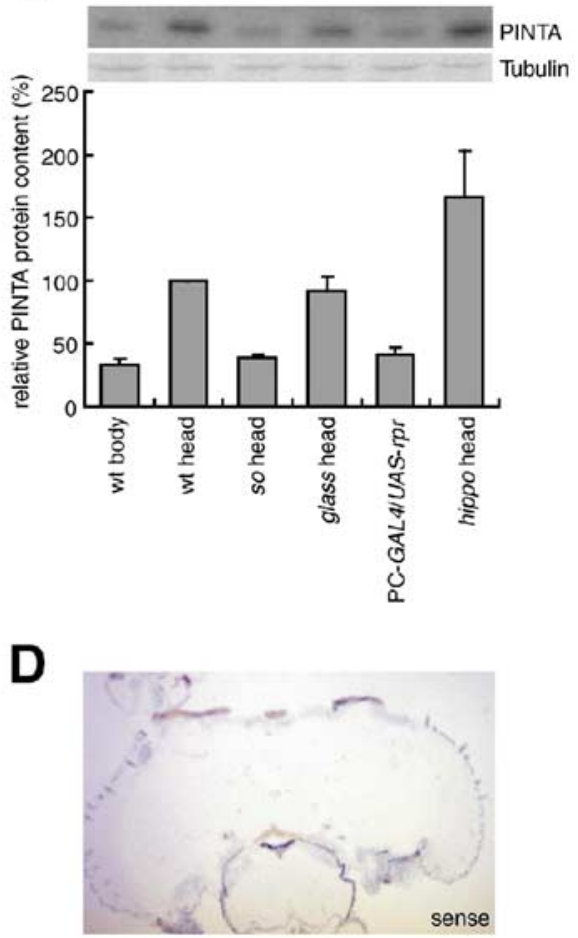

Figure 6. PINTA expressed in retinal pigment cells. $\boldsymbol{A}$, Developmental Western blot probed with anti-PINTA antibodies. Samdigoxigenin-labeled RNA probes. C, Antisense pinta RNA probe. D, Sense pinta RNA probe. Br, Brain; L, lamina; M, medulla; R,

eration of the chromophore (Sarfare et al., 2005) 11-cis-retinal (11-cis-3-hydroxy-retinal in Drosophila) (Vogt and Kirschfeld, 1984; Goldsmith et al., 1986; Seki et al., 1986; Tanimura et al., 1986). A gap in our understanding of Drosophila vision concerns the identities of RBPs required for transformation of vitamin A to the chromophore. This conversion is of particular relevance to mammalian vision because such steps occur during the lightdriven rhodopsin cycle. Although the fly chromophore does not dissociate from the opsin after light excitation, both mammals and Drosophila are faced with a similar problem of converting vitamin A from the diet into 11-cis-retinal. In mammals, these metabolic events take place in the RPE. Thus, an additional question concerns the Drosophila cell type involved in the transformation of all-trans-retinol to the chromophore.

Several observations indicate that PINTA functions in the retinal pigment cells for a step subsequent to production of alltrans-retinol. These include the findings that PINTA is expressed in pigment cells and that the pinta phenotype is rescued fully by introduction of wild-type PINTA into pigment cells but not photoreceptor cells. Thus, PINTA is unlikely to function in the biosynthesis of the opsin, which occurs in the photoreceptor cells. Rather, these data suggest that PINTA functions in the metabolism of the chromophore. In support of this proposal, PINTA contains a CRAL-TRIO domain and binds preferentially to alltrans-retinol. Moreover, PINTA binds to all-trans-retinol with an affinity comparable with that of other RBPs. In contrast to the ninaB and ninaD phenotypes, which are rescued by dietary vitamin A, addition of vitamin A does not suppress the severity of the 
A

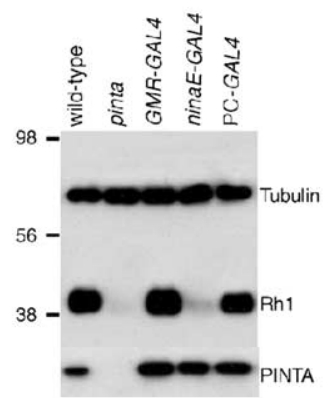

C

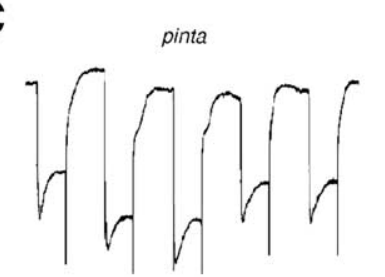

E

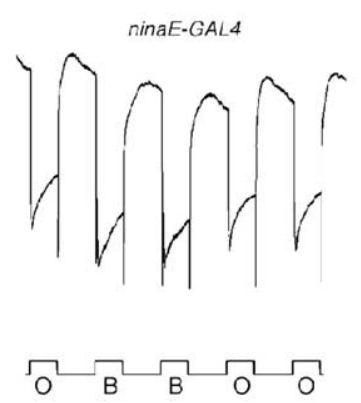

B

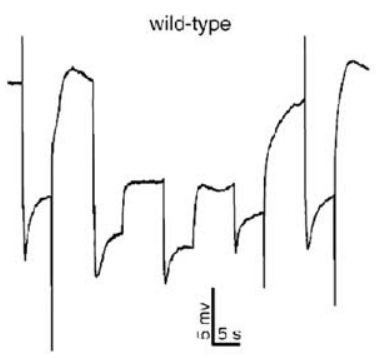

D

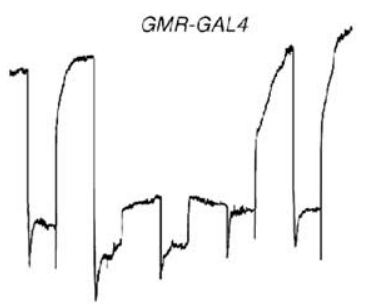

$\mathbf{F}$

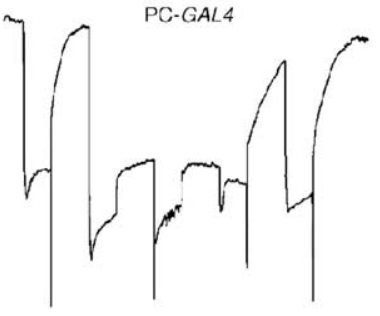

$\sqrt{\mathrm{B}}-{ }_{\mathrm{B}}-{ }_{\mathrm{O}}$
Figure 7. pinta functions in retinal pigment cells. $\boldsymbol{A}$, Examination of $\mathrm{Rh} 1$ protein levels after expression of PINTA in different sets of retinal cells using the GAL4/UAS system (Brand and Perrimon, 1993). A UAS-pinta transgene was introduced into pinta mutant flies. Expression of UAS-pinta was driven ubiquitously in the eye using a GMR-GAL4 or specifically in pigment or photoreceptor cells using PC-GAL4 (P[Gaw-B]LL54) or ninaE-GAL4, respectively. The Western blot was performed using extracts prepared from flies $2 \mathrm{~d}$ after eclosion. The same blot was probed with anti-Rh1, anti-tubulin, and anti-PINTA antibodies. $\boldsymbol{B}-\boldsymbol{F}$, ERG paradigm using blue light (B) and orange light $(0)$ as described in Figure 1A. B, PDA in wild-type $\left(w^{1118}\right)$ flies. $\boldsymbol{C}$, Absence of PDA in pinta flies. $\boldsymbol{D}-\boldsymbol{F}$, Directed expression of UAS-pinta in pinta mutant flies using the GAL4/UAS system. The following GAL4 lines were used: $\boldsymbol{D}, G M R-G A L 4 ; \boldsymbol{E}$, ninaE-GAL4; $\boldsymbol{F}$, PC-GAL4 (P[GaW-B]LL54).

pinta phenotype. Thus, pinta must function during a step downstream of vitamin A synthesis. The combination of these data suggests that the retinal pigment cells, which were not formerly implicated in the production of the photopigment, are the cells functionally most similar to those in the mammalian RPE.

Multiple RBPs have been described in mammals (for review, see Noy, 2000; Gonzalez-Fernandez, 2002). These include CRBPI, which also binds preferentially to all-trans-retinol (MacDonald and Ong, 1987; Levin et al., 1988). The RBP most related to PINTA is CRALBP, which binds primarily to either 11-cisretinal or 11-cis-retinol (Dong et al., 1999). However, introduction of transgenes encoding either CRALBP or CRBPI do not rescue the pinta phenotype (supplemental Fig. 2, available at www.jneurosci.org as supplemental material). Nevertheless, in contrast to pinta flies, a low level of Rh1 expression is detected in transgenic flies expressing CRALBP or CRBPI. Despite this small level of rescue of Rh1 levels, these data indicate differences in the specific roles of PINTA, CRALBP, and CRBPI and raise the pos- sibility that another RPE protein, which remains to be identified, may be the functional homolog of PINTA in mammals.

We propose that PINTA functions to sequester all-transretinol in retinal pigment cells, thereby generating a concentration gradient that promotes uptake of vitamin A in these cells. An alternative but not mutually exclusive possibility is that PINTA facilitates the presentation of all-trans-retinol to the enzymes and other proteins that participate in the next step of the visual cycle, the oxidation of all-trans-retinol to all trans-retinaldehyde.

It is worth noting that the effects on opsin concentration resulting from defects in chromophore production are quite different in vertebrates and invertebrates. In Drosophila, failure to produce the chromophore results in loss of the opsin. However, a defect in chromophore production in the mouse, such as occurs in the Rpe $65^{-/-}$mutant, does not eliminate the opsin (Redmond et al., 1998). This distinction may reflect the fact that the chromophore dissociates from mammalian opsins in a lightdependent manner, whereas it is always bound to invertebrate opsins. Interestingly, it has been proposed that the chromophore does not dissociate in a light-dependent manner from the mammalian melanopsin (Foster, 2005), which is expressed in a small subset of retinal ganglion cells that functions in circadian rhythm (Freedman et al., 1999; Provencio et al., 2000; Berson et al., 2002; Hattar et al., 2002; Panda et al., 2002; Ruby et al., 2002). Thus, it will be interesting to address whether defects in chromophore production eliminate the apoprotein in these retinal ganglion cells, as occurs in fly photoreceptor cells.

Finally, the current work raises the possibility that the remaining proteins required for biosynthesis of the chromophore function in the primary pigment cells. In the mammalian RPE, there are several alternative reactions through which all-trans-retinol is ultimately converted into the chromophore, 11-cis-retinal, and mutations in several genes that function in these events cause retinal diseases (Thompson and Gal, 2003). Although the proteins involved in the corresponding metabolic events have not been identified in Drosophila, it is intriguing that there are several genes expressed primarily in the fly eye that encode proteins related to those known to function in the mammalian visual cycle. These include three eye-enriched short-chain dehydrogenases (Xu et al., 2004), which may correspond to one or more retinal dehydrogenases. Whether these eye-enriched genes and ninaG are expressed and function in the retinal pigment cells to promote biosynthesis of the chromophore remains to be determined.

\section{References}

Astrom A, Tavakkol A, Pettersson U, Cromie M, Elder JT, Voorhees JJ (1991) Molecular cloning of two human cellular retinoic acid-binding proteins (CRABP). Retinoic acid-induced expression of CRABP-II but not CRABP-I in adult human skin in vivo and in skin fibroblasts in vitro. J Biol Chem 266:17662-17666.

Bernstein PS, Choi SY, Ho YC, Rando RR (1995) Photoaffinity labeling of retinoic acid-binding proteins. Proc Natl Acad Sci USA 92:654-658.

Berson DM, Dunn FA, Takao M (2002) Phototransduction by retinal ganglion cells that set the circadian clock. Science 295:1070-1073.

Bloomquist BT, Shortridge RD, Schneuwly S, Perdew M, Montell C, Steller H, Rubin G, Pak WL (1988) Isolation of a putative phospholipase C gene of Drosophila, norpA, and its role in phototransduction. Cell 54:723-733.

Brand AH, Perrimon N (1993) Targeted gene expression as a means of altering cell fates and generating dominant phenotypes. Development 118:401-415.

Chou WH, Hall KJ, Wilson DB, Wideman CL, Townson SM, Chadwell LV, Britt SG (1996) Identification of a novel Drosophila opsin reveals specific patterning of the R7 and R8 photoreceptor cells. Neuron 17:1101-1115.

Chou WH, Huber A, Bentrop J, Schulz S, Schwab K, Chadwell LV, Paulsen R, Britt SG (1999) Patterning of the R7 and R8 photoreceptor cells of Dro- 
sophila: evidence for induced and default cell-fate specification. Development 126:607-616.

Cogan U, Kopelman M, Mokady S, Shinitzky M (1976) Binding affinities of retinol and related compounds to retinol binding proteins. Eur J Biochem 65:71-78.

Colley NJ, Baker EK, Stamnes MA, Zuker CS (1991) The cyclophilin homolog NinaA is required in the secretory pathway. Cell 67:255-263.

Crabb JW, Johnson CM, Carr SA, Armes LG, Saari JC (1988) The complete primary structure of the cellular retinaldehyde-binding protein from bovine retina. J Biol Chem 263:18678-18687.

De Couet HG, Tanimura T (1987) Monoclonal antibodies provide evidence that rhodopsin in the outer rhabdomeres of Drosophila melanogaster is not glycosylated. Eur J Cell Biol 44:50-56.

Dong D, Ruuska SE, Levinthal DJ, Noy N (1999) Distinct roles for cellular retinoic acid-binding proteins I and II in regulating signaling by retinoic acid. J Biol Chem 274:23695-23698.

Fortini ME, Rubin GM (1990) Analysis of cis-acting requirements of the $R h 3$ and $R h 4$ genes reveals a bipartite organization to rhodopsin promoters in Drosophila melanogaster. Genes Dev 4:444-463.

Foster RG (2005) Neurobiology: bright blue times. Nature 433:698-699.

Freedman MS, Lucas RJ, Soni B, von Schantz M, Munoz M, David-Gray Z, Foster R (1999) Regulation of mammalian circadian behavior by nonrod, non-cone, ocular photoreceptors. Science 284:502-504.

Goldsmith TH, Marks BC, Bernard GD (1986) Separation and identification of geometric isomers of 3-hydroxyretinoids and occurrence in the eyes of insects. Vision Res 26:1763-1769.

Gonzalez-Fernandez F (2002) Evolution of the visual cycle: the role of retinoid-binding proteins. J Endocrinol 175:75-88.

Gu G, Yang J, Mitchell KA, O’Tousa JE (2004) Drosophila NinaB and NinaD act outside of retina to produce rhodopsin chromophore. J Biol Chem 279:18608-18613.

Harris WA, Ready DF, Lipson ED, Hudspeth AJ, Stark WS (1977) Vitamin A deprivation and Drosophila photopigments. Nature 266:648-650.

Hattar S, Liao HW, Takao M, Berson DM, Yau KW (2002) Melanopsincontaining retinal ganglion cells: architecture, projections, and intrinsic photosensitivity. Science 295:1065-1070.

Huber A, Schulz S, Bentrop J, Groell C, Wolfrum U, Paulsen R (1997) Molecular cloning of Drosophila Rh6 rhodopsin: the visual pigment of a subset of R8 photoreceptor cells. FEBS Lett 406:6-10.

Kiefer C, Sumser E, Wernet MF, Von Lintig J (2002) A class B scavenger receptor mediates the cellular uptake of carotenoids in Drosophila. Proc Natl Acad Sci USA 99:10581-10586.

Levin MS, Locke B, Yang NC, Li E, Gordon JI (1988) Comparison of the ligand binding properties of two homologous rat apocellular retinolbinding proteins expressed in Escherichia coli. J Biol Chem 263:17715-17723.

Li E, Locke B, Yang NC, Ong DE, Gordon JI (1987) Characterization of rat cellular retinol-binding protein II expressed in Escherichia coli. J Biol Chem 262:13773-13779.

MacDonald PN, Ong DE (1987) Binding specificities of cellular retinolbinding protein and cellular retinol-binding protein, type II. J Biol Chem 262:10550-10556.

Mata NL, Radu RA, Clemmons RC, Travis GH (2002) Isomerization and oxidation of vitamin a in cone-dominant retinas: a novel pathway for visual-pigment regeneration in daylight. Neuron 36:69-80.

Mey J, McCaffery P (2004) Retinoic acid signaling in the nervous system of adult vertebrates. Neuroscientist 10:409-421.

Montell C (1999) Drosophila visual transduction. Annu Rev Cell Dev Biol 15:231-268.

Montell C, Jones K, Zuker C, Rubin G (1987) A second opsin gene expressed in the ultraviolet-sensitive R7 photoreceptor cells of Drosophila melanogaster. J Neurosci 7:1558-1566.

Noy N (2000) Retinoid-binding proteins: mediators of retinoid action. Biochem J 348:481-495.

O’Tousa JE, Baehr W, Martin RL, Hirsh J, Pak WL, Applebury ML (1985) The Drosophila ninaE gene encodes an opsin. Cell 40:839-850.

Pak WL, Leung HT (2003) Genetic approaches to visual transduction in Drosophila melanogaster. Receptors Channels 9:149-167.

Panagabko C, Morley S, Hernandez M, Cassolato P, Gordon H, Parsons R,
Manor D, Atkinson J (2003) Ligand specificity in the CRAL-TRIO protein family. Biochemistry 42:6467-6474.

Panda S, Sato TK, Castrucci AM, Rollag MD, DeGrip WJ, Hogenesch JB, Provencio I, Kay SA (2002) Melanopsin (Opn4) requirement for normal light-induced circadian phase shifting. Science 298:2213-2216.

Papatsenko D, Sheng G, Desplan C (1997) A new rhodopsin in R8 photoreceptors of Drosophila: evidence for coordinate expression with Rh3 in R7 cells. Development 124:1665-1673.

Provencio I, Rodriguez IR, Jiang G, Hayes WP, Moreira EF, Rollag MD (2000) A novel human opsin in the inner retina. J Neurosci 20:600-605.

Redmond TM, Yu S, Lee E, Bok D, Hamasaki D, Chen N, Goletz P, Ma JX, Crouch RK, Pfeifer K (1998) Rpe65 is necessary for production of 11cis-vitamin A in the retinal visual cycle. Nat Genet 20:344-351.

Ruby NF, Brennan TJ, Xie X, Cao V, Franken P, Heller HC, O’Hara BF (2002) Role of melanopsin in circadian responses to light. Science 298:2211-2213.

Sarfare S, Ahmad ST, Joyce MV, Boggess B, O'Tousa JE (2005) The Drosophila nina $G$ oxidoreductase acts in visual pigment chromophore production. J Biol Chem 280:11895-11901.

Sato Y, Arai H, Miyata A, Tokita S, Yamamoto K, Tanabe T, Inoue K (1993) Primary structure of $\alpha$-tocopherol transfer protein from rat liver. Homology with cellular retinaldehyde-binding protein. J Biol Chem 268:17705-17710.

Seki T, Fujishita S, Ito M, Matsuoka N, Kobayashi C, Tsukida K (1986) A fly, Drosophila melanogaster, forms 11-cis 3-hydroxyretinal in the dark. Vision Res 26:255-258.

Simoni D, Tolomeo M (2001) Retinoids, apoptosis and cancer. Curr Pharm Des 7:1823-1837.

Stephenson RS, O’Tousa J, Scavarda NJ, Randall LL, Pak WL (1983) Drosophila mutants with reduced rhodopsin content. In: The biology of photoreception (Cosens D, Vince-Prue d, eds), pp 477-501. Cambridge, UK: Cambridge UP.

Szolderits G, Hermetter A, Paltauf F, Daum G (1989) Membrane properties modulate the activity of a phosphatidylinositol transfer protein from the yeast, Saccharomyces cerevisiae. Biochim Biophys Acta 986:301-309.

Tanimura T, Isono K, Tsukahara Y (1986) 3-Hydroxyretinal as a chromophore of Drosophila melanogaster visual pigment analyzed by high pressure liquid chromatography. Photochem Photobiol 43:225-228.

Thompson DA, Gal A (2003) Vitamin A metabolism in the retinal pigment epithelium: genes, mutations, and diseases. Prog Retin Eye Res 22:683-703.

Thummel CS, Pirrotta V (1992) New pCaSpeR P element vectors. Drosoph Inf Serv 71:150.

Udan RS, Kango-Singh M, Nolo R, Tao C, Halder G (2003) Hippo promotes proliferation arrest and apoptosis in the Salvador/Warts pathway. Nat Cell Biol 5:914-920.

Vogt K, Kirschfeld K (1984) Chemical identity of the chromophores of fly visual pigment. Naturwissenschaften 71:211-213.

von Lintig J, Dreher A, Kiefer C, Wernet MF, Vogt K (2001) Analysis of the blind Drosophila mutant ninaB identifies the gene encoding the key enzyme for vitamin A formation in vivo. Proc Natl Acad Sci USA 98:1130-1135.

Wald G (1968) The molecular basis of visual excitation. Nature 219:800-807.

Wang T, Xu H, Oberwinkler J, Gu Y, Hardie RC, Montell C (2005) Light activation, adaptation, and cell survival functions of the $\mathrm{Na}^{+} / \mathrm{Ca}^{2+}$ exchanger CalX. Neuron 45:367-378.

Wes PD, Xu X-ZS, Li H-S, Chien F, Doberstein SK, Montell C (1999) Termination of phototransduction requires binding of the NINAC myosin III and the PDZ protein INAD. Nat Neurosci 2:447-453.

Wu S, Huang J, Dong J, Pan D (2003) hippo encodes a Ste-20 family protein kinase that restricts cell proliferation and promotes apoptosis in conjunction with salvador and warts. Cell 114:445-456.

Xu H, Lee SJ, Suzuki E, Dugan KD, Stoddard A, Li HS, Chodosh LA, Montell C (2004) A lysosomal tetraspanin associated with retinal degeneration identified via a genome-wide screen. EMBO J 23:811-822.

Zuker CS, Cowman AF, Rubin GM (1985) Isolation and structure of a rhodopsin gene from D. melanogaster. Cell 40:851-858. 